\title{
Clinical profile of cardiac myxoma: 11 years' experience of 90 cases
}

Md. Toufiqur Rahman ${ }^{1}$, Md. Zulfikar Ali²; Md. Humayun Kabir 3 ; STM Abu Azam4, AAS Majumder ${ }^{5}$, Afzalur Rahman ${ }^{6}$, Syed Azizul Haque ${ }^{7}$

\begin{abstract}
:
Introduction: Cardiac myxoma is a benign neoplasm that represents the most common primary tumour of the heart. Because of nonspecific symptoms, early diagnosis may be a challenge. Although the left atrium is the most commonly involved site of origin in $75 \%$ of cases, it can arise from any of the cardiac chambers. Symptoms from a cardiac myxoma are more pronounced when the myxomas are left-sided, racemosus, and over $5 \mathrm{~cm}$ in diameter. Symptoms are produced by mechanical interference with cardiac function or embolization. Being intravascular and friable, myxomas account for most cases of tumor embolism. The site of embolism is dependent upon the location (left or right atrium) and the presence of an intracardiac shunt. Most atrial myxomas are benign and can be removed by surgical resection.
\end{abstract}

Objectives: To see clinical presentation and echocardiographic profile of cardiac myoxomas.
Methods: 90 cardiac myxoma patients who admitted both in cardiology and cardiac surgery departments of National Institute of Cardiovascular Diseases (NICVD), Dhaka from August 2003 to July, 2014 were studied clinically and by echocardiogram. Clinical histories were reviewed, noting age, gender, and clinical presentation.

Results: There were $\mathbf{3 0}$ males and $\mathbf{6 0}$ females, ages ranged from 17 to 76 years. The commonest clinical feature was dyspnoea (94.44\%), followed by palpitation $(76.67 \%)$, chest discomfort $(74.44 \%)$, constitutional symptoms $(50 \%)$, pedal oedema $(20 \%)$, syncope $(14.44 \%)$, and embolization $(7.7 \%)$. The mean duration of symptoms was 09.7 months.

Conclusion: The clinical presentation of cardiac myxoma is often nonspecific, so high index of clinical suspicion is important for its early and correct diagnosis. The size and appearance of the myxomas correlated with the presenting symptoms.

Key Words: Cardiac myxoma, Clinical presentation, Echocardiographic profile

(Bangladesh Heart Journal 2016; 31(1) : 18-22)

Introduction:

Cardiac myxoma is a benign neoplasm that represents the most common primary tumour of the heart. Because of nonspecific symptoms, early diagnosis may be a

1. Associate Professor, Department of Cardiology, National Institute of Cardiovascular Diseases, Dhaka.

2. Associate Professor, Department of Cardiology, National Institute of Cardiovascular Diseases, Dhaka.

3. Assistant Professor, Department of Cardiology, National Institute of Cardiovascular Diseases, Dhaka.

4. Ex-Director and Professor, Department of Cardiology, National Institute of Cardiovascular Diseases, Dhaka.

5. Director and Professor, Department of Cardiology, National Institute of Cardiovascular Diseases, Dhaka.

6. Professor, Department of Cardiology, National Institute of Cardiovascular Diseases, Dhaka.

7. Professor, Department of Cardiology, Dinajpur Medical College, Dinajpur. challenge. Although the left atrium is the most commonly involved site of origin in $75 \%$ of cases, it can arise from any of the cardiac chambers. Symptoms from a cardiac myxoma are more pronounced when the myxomas are left-sided, racemosus, and over $5 \mathrm{~cm}$ in diameter. Symptoms are produced by mechanical interference with cardiac function or embolization. Being intravascular and friable, myxomas account for most cases of tumor embolism. The site of embolism is dependent upon the location (left or right atrium) and the presence of an intracardiac shunt. Most atrial myxomas are benign and can be removed by surgical resection. ${ }^{1-5}$

Primary tumours of the heart are extremely rare, with an estimated incidence ranged from $0.0017 \%$ to $0.33 \%$ at autopsy ${ }^{1}$. Cardiac myxomas represent the most frequent 
benign cardiac tumors. In most surgical series, they account for almost $80 \%$ of cases. ${ }^{2}$ The cells giving rise to the tumor are considered to be multipotential mesenchymal cells that persist as embryonal residues during septation of the heart. ${ }^{3,4}$ They also are thought to arise from cardiomyocyte progenitor cells, subendothelial vasoformative reserve cells or primitive cells which reside in the fossa ovalis and surrounding endocardium or endocardial sensory nerve..$^{5-8}$ Occasionally, mucous glandular epithelium may present, which may represent rests of entrapped embryonic foregut. 9,10 Two types of macroscopic appearance are observed: polypoid type and papillary type. ${ }^{11,12}$ The histopathological diagnosis of a cardiac myxoma depends on the identification of the myxoma cell, which has occasionally been called the lepidic cell. ${ }^{13}$ The cells are arranged singly or in small clusters, or formed capillary like channels. ${ }^{2}$ Some morphological and immunohistochemical features may be related to the clinical presentations. Burke 4 found that embolic myxomas were less often fibrotic than nonembolic myxomas and were more likely thrombosed and extensively myxoid with an irregular frond-like surface. Fibrotic and non-thrombosed tumors had a longer mean duration of clinical symptoms and were found in older persons. Recurrent, multiple, and familial myxomas were more often found in younger women and, more likely irregular surfaced and histologically myxoid. Endo's group reported that tumors associated with constitutional signs were significantly more likely to be large, multiple, or recurrent than those unassociated with constitutional signs. ${ }^{14}$ Papillary surface myxomas are thought to be related to embolism, and large left atrial tumors are related to atrial fibrillation. Myxoma cells usually express IL-6, and some tumors have abnormal cellular DNA content. ${ }^{15}$ A C769T PRKAR1a mutation has been observed in "familial myxomas". 16

\section{Methods:}

90 cardiac myxoma patients who were admitted both in cardiology and cardiac surgery department in the National Institute of Cardiovascular Diseases (NICVD), Dhaka from August 2003 to July, 2014 were studied clinically and by echocardiogram. Clinical histories were reviewed, noting age, gender, and clinical presentation.

\section{Results:}

There were 30 males and 60 females, ages ranged from 17 to 76 years. The commonest clinical feature was dyspnoea $(94.44 \%)$, followed by palpitation $(76.67 \%)$, chest discomfort $(74.44 \%)$, constitutional symptoms $(50 \%)$, pedal oedema $(20 \%)$, syncope $(14.44 \%)$, and embolization (7.7\%). The mean duration of symptoms was 09.7 months.

Table-I

Presenting features of the patients. $(n=90)$

\begin{tabular}{lc}
\hline Clinical features & Percentage \\
\hline Dyspnoea & $85(94.44 \%)$ \\
Constitutional symptoms & $45(50 \%)$ \\
embolization & $07(7.77 \%)$ \\
palpitation & $69(76.67 \%)$ \\
syncope & $13(14.44 \%)$ \\
Pedal edema & $18(20 \%)$ \\
Chest discomfort & $67(74.44 \%)$ \\
\hline
\end{tabular}

Table-II

Sites of myxoma $(n=90)$

\begin{tabular}{lc}
\hline Site & No $(\%)$ \\
\hline Left atrium & $80(88.89 \%)$ \\
Right atrium & $07(07.78 \%)$ \\
Biatrial & $02(02.22 \%)$ \\
Right ventricle & $01(01.11 \%)$ \\
\hline
\end{tabular}

Only in $7.9 \%$ cases was the diagnosis of myxomas made clinically. $73.7 \%$ cases were initially diagnosed as having mitral valve disease, tricuspid valve disease $(09 \%)$, ischemic heart disease $(3.4 \%)$, cardiomyopathy (1.7\%), and the remaining $4.3 \%$ were detected during family screening and follow-up. The sites of myxomas were left atrium $80(88.89 \%)$; right atrium $07(07.78 \%)$ and biatrial $02(02.22 \%)$. All myxomas except 5 were attached to the interatrial septum. The site, size, shape, attachment, mobility, prolapse into ventricle, and surface characteristic of myxomas were accurately assessed by $2 \mathrm{D}$-echocardiography. When the morphological characteristic of myxomas were studied and correlated with clinical features, large left atrial myxomas presented more commonly with constitutional symptoms, congestive heart failure, syncope, and auscultatory findings suggestive of mitral valve disease, whereas myxomas smaller in size and with irregular surface were associated with embolization.

\section{Discussion:}

Myxoma is the most common primary cardiac neoplasm and accounts for approximately one-half of all primary cardiac tumors. ${ }^{1}$ Because of the nonspecific clinical presentation of patients with cardiac myxomas, premortem diagnosis was not accomplished until 1952, when Goldberg et al. ${ }^{13}$ demonstrated a left atrial myxoma 
at cardiac angiography. The first successful surgical resection of a cardiac myxoma was performed with a cardiopulmonary bypass in $1954 . .^{14,15}$

In concurrence with our series, patients with cardiac myxomas are reported to have a wide age range (17-76 years), with a mean age of approximately 45 years. There appears to be a slight female predominance, with a female-to-male ratio of 5:4.1, 5, 15-17 $95 \%$ of our patients presented with at least one manifestation of a classically described clinical triad, which includes cardiac obstructive symptoms, embolic phenomena, and constitutional symptoms. ${ }^{5}$

Presenting complaints relate to tumor location, which predicts obstructive sequelae and influences embolic sites (pulmonary or systemic). Left atrial myxomas commonly cause mitral valve obstruction, and symptoms mimic those of rheumatic heart disease. Affected patients present with dyspnea and orthopnea from pulmonary venous hypertension. ${ }^{1,} 5,15$ The pedunculated and prolapsing nature of these tumors allows for positional and intermittent mitral valve obstruction. Left atrial myxomas may present with symptoms related to mitral valve obstruction. Right atrial myxomas may obstruct the tricuspid valve and cause symptoms of right-sided heart failure, peripheral edema, passive hepatic congestion, and syncope. In our series, only $10 \%$ of patients with right atrial myxoma presented with signs and symptoms of tricuspid valve obstruction. Ventricular myxoma may also cause right-sided heart obstruction. . $^{5} 14$

Constitutional symptoms of fever, malaise, weight loss, anemia, and elevated erythrocyte sedimentation rate (ESR) have been reported and may be related to an autoimmune reaction initiated by the tumor. ${ }^{1,5,8,18}$ These symptoms were present in $50 \%$ of our patients. Cardiac arrhythmias, atrial fibrillation, and atrial flutter reportedly occur in approximately $20 \%$ of patients with cardiac myxoma. ${ }^{16,19}$ In our series, $69 \%$ of patients presented with arrhythmia or palpitation. Embolic phenomena are reported in approximately $35 \%$ of left-sided and $10 \%$ of right-sided myxomas. ${ }^{1,15,19,20}$. The propensity of cardiac myxomas to embolize is thought to be related to tumor morphology, with friable and gelatinous myxomas being more likely to embolize than firm and fibrous lesions. ${ }^{1,20,21}$ Left-sided myxomas embolize systemically, usually to the brain, kidneys, and lower extremities, and right-sided myxomas embolize to the pulmonary circulation. ${ }^{1,15,19}$. Approximately $20 \%$ of all patients with myxomas irrespective of intracardiac location are reportedly asymptomatic, and the tumors are discovered incidentally or at autopsy. ${ }^{22}$
The majority of cardiac myxomas occur sporadically. However, in approximately $7 \%$ of patients, cardiac myxomas exhibit atypical behavior, demonstrating a familial predisposition or an association with a clinical complex (Carney complex). These patients tend to be younger (mean age, 24 years) and male, and the myxomas are more likely to be multicentric $(45 \%)$ or recurrent $(12 \%-22 \%)$, whereas only $1 \%-3 \%$ of sporadic myxomas reportedly recur. ${ }^{3,4,23,24}$ Carney complex is an autosomal dominant condition with a complex of lesions that include mammary myxoid fibroadenoma, spotty pigmented lesions of the skin, endocrine disorders, testicular tumors, and psammomatous melanotic schwannoma. Two-thirds of these patients have cardiac myxomas. ${ }^{23,24}$

Cardiac myxoma is an intracavitary, round or ovoid neoplasm that is attached to the endocardium. Although the vast majority attach at the fossa ovalis of the interatrial septum, they can arise from any endocardial surface. ${ }^{1}$ The majority $(75 \%)$ occur in the left atrium, with a smaller proportion in the right atrium (20\%) and rare cases in right ventricular, biatrial, left ventricular, or multiple locations. ${ }^{1,15,25}$ In our series, approximately two-thirds of the atrial myxomas were attached to the interatrial septum, and the tumor location differed slightly from most reports, with $88 \%$ arising from the left atrium and $7 \%$ from the right atrium.

The clinical presentation of myxomas is diverse and dependent upon tumor location, size and mobility 24-27. According to a previous study, the most common symptom is dyspnea (54\%), and then followed by palpitation (35\%). ${ }^{15}$ Dyspnea and edema of lower limbs are thought to a consequence of atrioventricular valve obstruction. Nevertheless, the intracardiac obstruction may also lead to narrowing outflow tract and atrial fibrillation, which could contribute to dyspnea and palpitation. Cough is thought to result in pulmonary venous hypertension and frank pulmonary edema. Angina may be caused by insufficient blood supply. Embolism is also a classic symptom of myxomas, which have been reported to associate with the papillary surface 15. The cause of some constitutional disturbances is still unclear. Some findings suggest the cytokine interleukin6 (IL-6) may be responsible for that. The relationship between IL- 6 and constitutional syndromes is still controversial. In some cases, the right atrial myxomas may induce pulmonary hypertension because of embolism of tumor fragments. Right ventricular myxomas may mimic stenosis of pulmonary valve and cause syncope. In our series, both left and right atrial myxomas 
were observed with symptoms of dyspnea, palpitation, cough, and angina. Besides, two cases presented with cerebral infarction symptoms and one case with angina and vertigo showed papillary surface, which was consistent with previous studies. ${ }^{4,15}$ Other cerebral symptoms in cases of solid surface may only caused by cardiac obstruction and cerebral ischemia. About $20 \%$ of cardiac myxomas are asymptomatic; they are usually smaller than $4 \mathrm{~cm}{ }^{28,} 29$. The maximal diameter of four asymptomatic cases of the present report was $6,4,3$, and $3 \mathrm{~cm}$, respectively. We consider it is due to the small tumor size or long growth course, which may result in adaption to the tumor.

Echocardiography is widely recognized as a sensitive preoperative diagnostic method, although it appears nonspecific to some occupying lesions. Moreover, thrombus may be misdiagnosed as myxoma in some cases. Nevertheless, echocardiography is also demonstrated as the most accurate and reliable preoperative method with which to predict the diameter, location, attachment, mobility, and morphology of cardiac myxomas.

Bone and brain metastases from glandular cardiac myxomas have been reported in the recent literature. ${ }^{31-}$

${ }^{38}$ The most frequent metastatic site for cardiac myxomas is cerebrum. ${ }^{33}$ Several reports have reviewed cerebral metastasis cases. ${ }^{34,35}$ Since most myxomas are located in the left atrium, systemic embolism is particularly frequent. The tumor fragments metastasized to cerebral vessel walls may penetrate through the vessel wall, forming intra-arterial metastases. Some cytokines, such as CXC chemokines, may explain the metastasis potential of morphologically benign myxomas. In our series, no metastatic case was observed.

\section{Conclusion:}

The clinical presentation of cardiac myxoma is often nonspecific, and may be detected in asymptomatic patients, so a high index of clinical suspicion is important for its early and correct diagnosis. The size and appearance of the myxomas correlate with the presenting symptoms.

\section{References:}

1. Wold LE, Lie JT. Cardiac myxomas: a clinicopathologic profile. Am J Pathol 1980;101:219-40.

2. Burke AP, Tazelaar H, Gomez-Roman JJ, et al. Cardiac myxoma. In: Travis WD, Brambilla E, MullerHermelink HK, Harris CC, editors. Pathology and Genetics of Tumours of the Lung, Pleura, Thymus and Heart. Lyon: IARC Press, 2004: 260-3.
3. Rahman MT. Clinical and echocardiographic profile of cardiac myxoma. Global Heart 2014;9(1):e321.

4. Burke AP, Virmani R. Cardiac myxoma. A clinicopathologic study. Am J Clin Pathol 1993;100:671-80.

5. Markel ML, Waller BF, Armstrong WF. Cardiac myxoma: a review. Medicine 1987; 66:114-25.

6. Terracciano LM, Mhawech P, Suess $K$, et al. Calretinin as a marker for cardiac myxoma. Diagnostic and histogenetic considerations. Am J Clin Pathol 2000;114:754-9.

7. Pucci A, Gagliardotto P, Zanini C, et al. Histopathologic and clinical characterization of cardiac myxoma: review of 53 cases from a single institution. Am Heart J 2000;140:134-8.

8. Amano J, Kono T, Wada Y, et al. Cardiac myxoma: its origin and tumor characteristics. Ann Thorac Cardiovasc Surg 2003;9:215-21.

9. Alam MS Haque SA, Rahman MT, Chowdhury MA, Khair MA. Varied presentation of atrial myxoma: Report of six cases. Chest and Heart Journal 2004;28(02):80-3.

10. Pucci A, Bartoloni G, Tessitore E, et al. Cytokeratin profile and neuroendocrine cells in the glandular component of cardiac myxoma. Virchows Arch 2003;443:618-24.

11. Reynen K. Cardiac myxomas. N Engl J Med 1995;333:1610-7.

12. Butany J, Nair V, Naseemuddin A, et al. Cardiac tumours: diagnosis and management. Lancet Oncol 2005;6:219-28.

13. St John Sutton MG, Mercier LA, Giuliani ER, et al. Atrial myxomas: a review of clinical experience in 40 patients. Mayo Clin Proc 1980;55:371-6.

14. Endo A, Ohtahara A, Kinugawa $T$, et al. Characteristics of cardiac myxoma with constitutional signs: a multicenter study in Japan. Clin Cardiol 2002;25:367-70.

15. Bjessmo S, Ivert T. Cardiac myxoma: 40 years' experience in 63 patients. Ann Thorac Surg 1997; 63:697-700.

16. Yokomuro $\mathrm{H}$, Yoshihara $\mathrm{K}$, Watanabe $\mathrm{Y}$, et al. The variations in the immunologic features and interleukin-6 levels for the surgical treatment of cardiac myxomas. Surg Today 2007;37:750-3. 
17. Wang JG, Wei ZM, Liu H, et al. Primary pleomorphic liposarcoma of pericardium. Interact Cardiovasc Thorac Surg 2010;11:325-7.

18. Kumar BV, Abbas AK, Fausto N, et al. Cardiac tumors. In: Kumar BV, Abbas AK, Fausto N, Mitchell $\mathrm{R}$, editors. Robbins basic pathology, 8th edition. Philadelphia: Saunders, 2007: 417-8.

19. Castells E, Ferran V, Octavio-de-Toledo MC. Cardiac myxomas: surgical treatment, long-term results and recurrence. J Cardiovasc Surg 1993; 34:49-53.

20. Moriyama Y, Saigenji H, Shimokawa S, Toyohira H, Taira A. The surgical treatment of 30 patients with cardiac myxomas: a comparison of clinical features according to morphological classification. Surg Today 1994; 24:596-598.

21. Larsson S, Lepore V, Kennergren C. Atrial myxomas: results of 25 years' experience and review of the literature. Surgery 1989;105:695-8.

22. Edwards A, Bermudez C, Piwonka G, et al. Carney's syndrome: complex myxomas. Report of four cases and review of the literature. Cardiovasc Surg 2002;10:264-75

23. Islam AKMM, Rahman MT, Paul TK. Biatrial myxoma in a young male patient. Korean Circ J. 2011;41(12):770-1.

24. Premaratne S, Hasaniya NW, Arakaki HY, et al. Atrial myxomas: experiences with 35 patients in Hawaii. Am J Surg 1995;169:600-3.

25. Bjessmo S, Ivert T. Cardiac myxoma: 40 years' experience in 63 patients. Ann Thorac Surg 1997;63:697-700.

26. Pinede L, Duhaut $P$, Loire R. Clinical presentation of left atrial cardiac myxoma. A series of 112 consecutive cases. Medicine (Baltimore) 2001;80:159-72.

27. Gabe ED, Rodríguez Correa C, Vigliano C, et al. [Cardiac myxoma. Clinical-pathological correlation]. Rev Esp Cardiol 2002;55:505-13.
28. Goswami KC, Shrivastava S, Bahl VK, et al. Cardiac myxomas: clinical and echocardiographic profile. Int J Cardiol 1998;63:251-9.

29. Grebenc ML, Rosado-de-Christenson ML, Green CE, et al. Cardiac myxoma: imaging features in 83 patients. Radiographics 2002;22:673-89.

30. Acebo E, Val-Bernal JF, Gómez-Roman JJ. Thrombomodulin, calretinin and c-kit (CD117) expression in cardiac myxoma. Histol Histopathol 2001;16:1031-6.

31. Moiyadi AV, Moiyadi AA, Sampath S, et al. Intracranial metastasis from a glandular variant of atrial myxoma. Acta Neurochir (Wien) 2007;149:1157-62.

32. Uppin SG, Jambhekar N, Puri A, et al. Bone metastasis of glandular cardiac myxoma mimicking a metastatic carcinoma. Skeletal Radiol 2011;40:107-11.

33. Shimono T, Makino S, Kanamori Y, et al. Left atrial myxomas. Using gross anatomic tumor types to determine clinical features and coronary angiographic findings. Chest 1995;107:674-9.

34. Lijoi A, Scoti P, Faveto C, et al. Surgical management of intracardiac myxomas: a 16 year experience. Tex Heart Inst J 1993; 20:231-4.

35. Rodrigues D, Matthews N, Scoones D, et al. Recurrent cerebral metastasis from a cardiac myxoma: case report and review of literature. $\mathrm{Br} \mathrm{J}$ Neurosurg 2006;20:318-20.

36. Link KM, Lesko NM. MR evaluation of cardiac/ juxtacardiac masses. Top Magn Reson Imaging $1995 ; 7: 232-45$.

37. Araoz PA, Eklund HE, Welch TJ, Breen JF. CT and MR imaging of primary cardiac malignancies. Radiographics. 1999 Nov-Dec;19(6):1421-34.

38. Edwards FH, Hale D, Cohen A, Thompson L, Pezzella T, Virmani R. Primary cardiac valve tumors. Ann Thorac Surg 1991; 52:1127-31. 